\title{
Predictors of adherence to isoniazid preventive therapy among HIV positive adults in Addis Ababa, Ethiopia
}

\author{
Mesele Mindachew ${ }^{1}$, Amare Deribew ${ }^{2}$, Fasil Tessema² and Sibhatu Biadgilign²*
}

\begin{abstract}
Background: Isoniazide preventive therapy (IPT) is given to individuals with latent infection of tuberculosis (TB) to prevent the progression to active disease. One of the primary reasons for failure of IPT is poor adherence.

Methods: A cross sectional study was conducted in four hospitals in Addis Ababa. Data were collected using a pre-tested interviewer-administered structured questionnaire. Bivariate and multivariate analysis was done to identify predictors of IPT.

Results: A total of 319 (97.5\%) individual participated in this study. Within seven days recall period, self-reported dose adherence rate was $86.5 \%$. Individual who received explanation about IPT from health care providers (OR $=$ 7.74; 95\%Cl: 3.144, 19.058); who had good feeling/comfortable to take IPT in front of other people [OR $=5.981$, $95 \% \mathrm{Cl}(2.308,15.502)]$ and who attended clinical appointment regularly $(\mathrm{OR}=4.0 ; 95 \% \mathrm{Cl}: 1.062,15.073)$ were more likely to adhere to IPT. Participants who developed IPT related adverse effect were $93 \%$ less likely to adhere to the prescribed doses $(\mathrm{OR}=0.065 ; 95 \% \mathrm{Cl}: 0.024,0.179)$.

Conclusion: The prevalence of self reported dose adherence over the past 7 days was higher. Non-adherence was observed among respondent who were not provided with sufficient information about IPT. The health care providers need to strengthen their educational and counseling efforts to convince the patient before putting them on IPT. To enhance adherence, health education efforts should focus on the importance of IPT, the details of the regimen and adverse effects.
\end{abstract}

Keywords: Adherence, TB, Isoniazid Preventive Therapy, HIV, Ethiopia

\section{Background}

Tuberculosis is among the top ten causes of global mortality and morbidity. Recently, 32\% of the world's population is infected with TB. Over $95 \%$ of new tuberculosis cases and deaths occur in developing countries where the highest incidence and number of deaths occur in Asia and sub-Saharan Africa [1]. HIV/AIDS is the greatest risk factors for the development of TB. The risk of reactivation of latent infection of $\mathrm{TB}$ is greatly increased in Africa as a result of the HIV/AIDS epidemic [2-5].

The World Health Organization (WHO) had proposed a framework of TB/HIV/AIDS collaborative activities to

\footnotetext{
* Correspondence: sibhatu2005@yahoo.com

${ }^{2}$ Department of Epidemiology, College of Public Health and Medical Science, Jimma University, Jimma, Ethiopia

Full list of author information is available at the end of the article
}

prevent the occurrence of TB-HIV disease. IPT, intensified TB case finding, and infection prevention are the major strategies to control TB in HIV-positive individuals [6]. Cognizant of this fact, the Ethiopia national TB/HIV collaboration program adopted these activities including IPT. The Ethiopian national TB guideline recommends that Isoniazide (INH) should be given to patients daily at a dose of $5 \mathrm{mg} / \mathrm{kg}$, a maximum dose of $300 \mathrm{mg} /$ day for a period of 6 months. Pyridoxine at a fixed daily dose of $25 \mathrm{mg}$ is indicated in order to reduce the risk of developing INH-induced peripheral neuropathy [7]. Tuberculosis preventive therapy should only be considered in areas that have a good functioning of tuberculosis program [8]. There is now strong evidence from several randomized controlled trials about the efficacy of preventive therapy in the prevention of

\section{Ciomed Central}


tuberculosis in persons infected with the human immunodeficiency virus. However, one of the primary reasons for failure of IPT is poor adherence. Accurate assessment of adherence and its associated factor is a necessary first step towards improving adherence to IPT [9]. There is limited knowledge in Ethiopia about the rate of adherence to IPT and its determinants. The aim of this study was to address this knowledge gap using a multicenter study in Addis Ababa, Ethiopia.

\section{Methods}

\section{Study setting and participants}

A cross sectional study was conducted in Yekatit 12, Zewditu, Gandi and Minilik hospitals in Addis Ababa from February 1 to March 30, 2010. The study hospitals are among the biggest in Ethiopia and serving the majority of the HIV/AIDS clients in the country. The hospital records showed that from the total of 1808 adults taking IPT in the whole Ethiopia, 1303 of them were attending in these hospitals.

The source populations were People Living with HIV/ AIDS (PLHA) without active TB attending the ART clinics of the study hospitals and, who were on IPT and on follow up during the study period. The study population was sampled adults who were receiving IPT and fulfilling the inclusion criteria in the study hospitals. Adult ( $>=18$ years) HIV positive individuals who were taking IPT for at least one month before the initiation of the study were included in the study. Individuals who had been taking IPT for less than a month and/or were seriously sick were excluded from the study.

\section{Sample size and sampling technique}

The sample size was calculated using Epi-Info 6.04 statistical software with the assumptions of adherence rate of $50 \%, 5 \%$ margin of error and $95 \%$ confidence interval and $10 \%$ for non-response rate. This gave us a total sample size of 327 . This sample size was distributed to the selected hospitals according to the number of patients proportionally. All HIV positive individuals attending the TB/HIV clinics of the selected hospitals and who fulfilled the entry criteria were identified from clinics using their identification number as a sampling frame. From the sampling frame, participants were selected using simple random sampling technique.

\section{Data collection process}

Data were collected by trained public health officers using a structured and pre-tested questionnaire. The questionnaire contained dependent and independent variables and was originally developed in English; and then translated into Amharic and back translated to English by other person who was blind to the original questionnaire to check for its consistency. The dependent variable was self-reported adherence to IPT in the last 3, 7 and 30 days. The independent variables included: socio-demographic variables, medication adverse effect, emotional and social support, convenience of regimen (the duration, dose, and frequency), knowledge about IPT and understanding the important of adherence; belief on the efficacy of medication; substance use such as Khat(Catha Edulis), alcohol, and cigarette; patient and physician relationship.

The percent of adherence was calculated for each drug by dividing the number of pills taken by the number of pills prescribed. Then, the percent of adherence to the IPT was estimated by the average adherence rate to the drugs.

\section{Data analysis}

The data were entered into SPSS 16.0, edited, and cleaned thoroughly and analyzed. The analysis consisted of basic summaries of patient characteristics, bivariate and multivariate analysis of the relation between adherence and various factors. All explanatory variables that were significantly associated with the outcome variable in the bivariate analyses $(P<0.05)$ were entered in stepwise logistic regression model to identify independent predictor of adherence. In this study, patients who report an intake of $80 \%$ or more of the prescribed medication over past 3 and 7 days were considered to be adherent, while a patient who reported an intake of less than $80 \%$ of the prescribed doses over the past 3 and 7 days were considered to be non adherent [10]. Adverse effect was also defined as an unwanted effect caused by the administration of INH such as numbness as a result of neuropathy, sign of liver toxicity, rash, nausea, and seizure. Ethical Clearance was obtained from Institutional Ethical Review Committee of Jimma University and ethical review committee of Addis Ababa Health Bureau.

\section{Results}

\section{Characteristics of the study subjects}

Of the proposed study participants, 319 (97.5\%) were included in this study. One hundred and twenty-four (38.9\%) were males and their age ranged from 22 to 71 years with the mean (SD) age of $38( \pm 10.6)$. Orthodox was the dominant religion (84.3\%) and 125 (39.2\%) were married. Almost half $172(53.9 \%)$ of the respondents were Amhara, and more than half of the respondent 203 (63\%) had average monthly income of less than 35.5 USD (1US \$ = 17Birr), 94(29.5\%) were grade 1-8 educational level, and $114(35.7 \%)$ were private institution employee (Table 1).

\section{Patient report on adherence to IPT}

As shown in Table 2, the 3 days, 7 days, and the past 1 month self-reported adherence rate was 281(88.1\%), 276 
Table 1 Basic socio-demographic attributes of the crosssectional survey at Addis Ababa governmental hospitals, Addis Ababa, May 2010

\begin{tabular}{|c|c|}
\hline Socio-demographic Variables & Frequency (\%) \\
\hline \multicolumn{2}{|l|}{ Sex $(n=319)$} \\
\hline Male & 124(38.9\%) \\
\hline Female & $195(61.1 \%)$ \\
\hline \multicolumn{2}{|l|}{ Age $38.7(+10.6)$ yrs $(n=319)$} \\
\hline$<25$ & $16(5)$ \\
\hline $25-34$ & $110(34.5)$ \\
\hline $35-44$ & 85 (26.6) \\
\hline$\geq 45$ & $108(33.9)$ \\
\hline \multicolumn{2}{|l|}{ Ethnicity ( $n=319$ ) } \\
\hline Oromo & $71(22.3)$ \\
\hline Ahmara & $172(53.9)$ \\
\hline Tigre & $48(15)$ \\
\hline Others" & $28(8.8)$ \\
\hline \multicolumn{2}{|l|}{ Religion ( $n=319$ ) } \\
\hline Orthodox & $269(84.3)$ \\
\hline Protestant & $33(10.3)$ \\
\hline Muslim & $15(4.7)$ \\
\hline Catholic & $2(0.6)$ \\
\hline \multicolumn{2}{|l|}{ Marital status $(n=319)$} \\
\hline Single & $66(20.7)$ \\
\hline Married & $125(39.2)$ \\
\hline Divorced & $39(12.2)$ \\
\hline Widowed & $89(27.9)$ \\
\hline \multicolumn{2}{|l|}{ Educational status( $\mathrm{n}=319)$} \\
\hline Illiterate & $40(12.5)$ \\
\hline Grade 1-8 & $94(29.5)$ \\
\hline Grade 9-10 & $39(12.2)$ \\
\hline Grade +10 and certificate & $93(29)$ \\
\hline Diploma and above & $52(16.3)$ \\
\hline \multicolumn{2}{|l|}{ Occupational status $(\mathrm{n}=319)$} \\
\hline House wife & $60(18.8)$ \\
\hline Student & $3(0.9)$ \\
\hline Government employment & $44(13.8)$ \\
\hline Private employee & $114(35.7)$ \\
\hline Merchant & $14(4.4)$ \\
\hline Driver & $5(1,6)$ \\
\hline No jobs & $71(22.3)$ \\
\hline Others* & $8(2.3)$ \\
\hline \multicolumn{2}{|l|}{ Monthly income $(n=319)$ in USD } \\
\hline$>=35.5$ & 203(63.6) \\
\hline$<35.5$ & $116(36.4)$ \\
\hline
\end{tabular}

\#Affar, Guragie, Somali, Welaita

*Clerical, Sales and services, Manual labor, Agriculture

${ }^{\$}$ Exchange rate 1 USD $=17$ Ethiopian Birr (ETB)
Table 2 IPT adherence status by self-reports of the crosssectional survey at Addis Ababa governmental hospitals, Addis Ababa, May 2010

\begin{tabular}{llll}
\hline Duration & $\begin{array}{l}\text { Adherent } \\
\text { Frequency } \\
\text { (\%) }\end{array}$ & $\begin{array}{l}\text { Non-adherent } \\
\text { Frequency (\%) }\end{array}$ & $\begin{array}{l}\text { Total } \\
\text { Frequency } \\
\text { (\%) }\end{array}$ \\
\hline $\begin{array}{l}\text { Past three } \\
\text { days }\end{array}$ & 281(88.1) & $38(11.9)$ & $319(100)$ \\
\hline Past 7 days & 276(86.5) & 43(13.5) & $319(100)$ \\
\hline $\begin{array}{l}\text { Past one } \\
\text { month }\end{array}$ & 255(79.9) & 64(20.1) & $319(100)$ \\
\hline
\end{tabular}

(86.5\%), and 255 (79.9\%) respectively. The average [SD] number of doses missed in the past 3 days, 7 days and 1 month prior to the study was $1.84[\mathrm{SD} \pm 0.75], 2.64$ [SD $\pm 0.1 .71]$ and $6.3[\mathrm{SD} \pm 7.31]$ respectively. Of the total participants, 66 (20.7\%) had history of missed days (missed one or more doses of isoniazide in the past 3 days, 7 days, in the last 1 month prior to enrolment in study)(Table 3). The most frequently mentioned reasons for missing pills were side effect $(18.19 \%, \mathrm{~N}=12)$, being too busy to take the drug $(22.72 \%, \mathrm{~N}=16)$, forgetfulness (24.24\%, $\mathrm{N}=15)$, perceived long duration of treatment $(13.63 \%, N=9)$, being away from residential area $(15.16 \%, \mathrm{~N}=10)$ and lack of advice by doctors $(6.06 \%$, $\mathrm{N}=4$ ) (Figure 1).

Factors independently associated with adherence to IPT Individual who had receive explanation about IPT were 8 times more likely to be adherent as compared to those who did not receive (OR $=7.740$; 95\%) CI: (3.144, 19.058). Patients who developed IPT related adverse effects were $93 \%$ less likely to adhere to the prescribed doses $(\mathrm{OR}=0.065$; 95\%CI: 0.024, 0.179). Study participants who had good feeling/comfortable to take IPT drug in front of others people were 6 times more likely

Table 3 Frequency table that shows patient's adherence practice of the cross-sectional survey at Addis Ababa governmental hospitals, Addis Ababa, May 2010

\begin{tabular}{cc}
\hline Variables & Frequency (\%) \\
\hline History of missed days & $66(20.7)$ \\
\hline Yes & $253(79.3)$ \\
\hline No & $29(51.8)$ \\
\hline Wime of missing prior to interview to interview & $17(30.4)$ \\
\hline Between 1-2 month & $4(7.1)$ \\
\hline Between 3-5 months & $2(3.6)$ \\
\hline Above 5 months & $4(7.1)$ \\
\hline I don't know
\end{tabular}




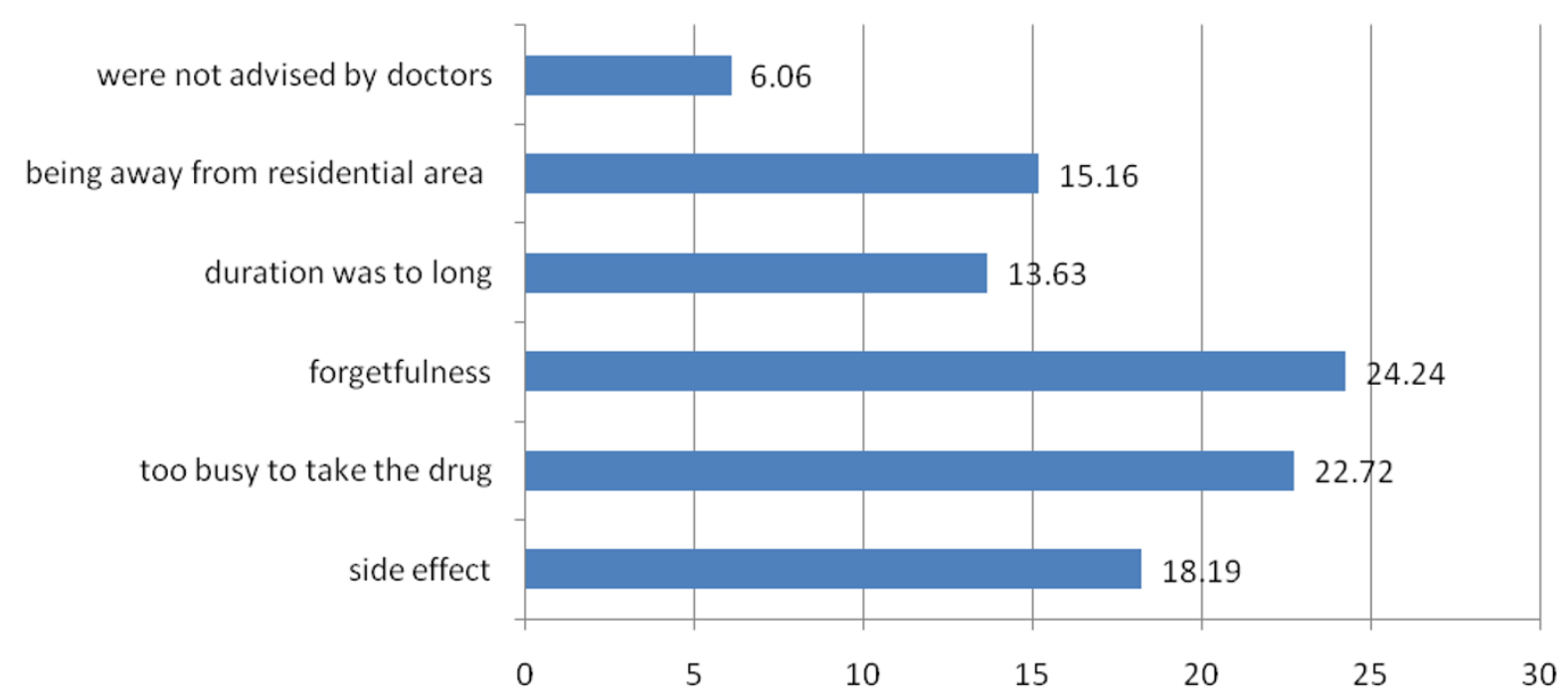

Figure 1 Reasons given for missing to take IPT among people living with HIV in Addis Ababa government hospitals, Addis Ababa, May 2010.

to adhere to the prescribed medication $(\mathrm{OR}=5.981$; 95\%CI: 2.308, 15.502) and those who attend clinical appointment regularly were 4 times more likely to adhere to IPT compared to those who did not attend regularly $(\mathrm{OR}=4.001 ; 95 \% \mathrm{CI}: 1.062,15.073)($ Table 1$)$.

\section{Discussion}

We tried to assess the rate of adherence to IPT and its determinants among HIV positive adults in the capital city of Ethiopia. We use self-reported dose adherence due to its ease of practicality, low cost, readiness to obtain the desired information, and to identify patients' at risk for non-adherence [11]. This study revealed an overall prevalence rate of IPT adherence rate of 276 [86.5\%] over the past 7 days prior to the interview. In the operational assessment of adherence among HIV infected individual in Uganda, adherence rate of 38\% was reported [11]. A facility based cross-sectional study in rural South Africa also found that only $47.1 \%$ were adherent to isoniazid preventive therapy [12]. In a prospective cohort study in Thailand using daily isoniazid for 6 months, 31\% failed to complete the 9-month regimen [13]. In contrast to these, a cross-sectional study in South Africa revealed relatively similar finding with the present study with overall rate of self reported adherence rate of 72\%[14] and a randomized control trail of adherence to IPT among HIV patient in Uganda also showed similar finding with adherence rate of $88 \%$ [15]. This may be due to the fact that majority of the respondent had receive the information about isoniazide preventive therapy and perceived benefit of the medication. In addition, it might be also due to the great emphasis given to the TB-HIV collaborative activity by the government and implementing partners. In the current study, different reasons for missing pills such as forgetfulness, being buss, and away from home were reported which is consistent with the findings of other studies $[16,17]$. In our study, patients' who didn't miss clinic appointment were more likely to complete their regimen which is similar to a study elsewhere [18].

According to a study conducted in Kenya and Zambia, the poor quality of physicians' interpersonal skills has been shown to negatively affect adherence $[19,20]$. Four cross-sectional studies showed the impact of poor patient-physician relation on adherence in different setting [21-24]. Randomized trial also showed that an increase in non-adherence in situations where doctors appear insensitive, use medical jargon, view patients as complainers, or do not provide clear messages about the cause of the illness or reasons for treatment $[25,26]$. Stigma or uncomfortable to take drug in front of others was one of the factors for adherence to IPT. A stigma attached to TB in China leads to imposition of sociophysical distance and participatory restrictions on those suffering from the disease [27] and social and family support positively influenced adherence [12] and reasons for low adherence to preventive INH treatment, other than side effects, include fear of stigma [18,28]. Patients' who developed side effect were less likely to complete the prescribed regimen. A systematic review of randomized trial showed that adherence has been shown to decrease with increased concerns about the toxicity of anti-TB medications and fear of side effects [15]. It is possible that minor adverse effects, which did not pose a danger in the clinician's view, nevertheless resulted in discomfort and contributed to a patients' decision not to 
Table 4 Independent predictors of adherence to IPT among people living with HIV in Addis Ababa government hospitals, Addis Ababa, May 2010

\begin{tabular}{|c|c|c|c|c|c|c|}
\hline Variable & $\begin{array}{l}\text { Adherent } \\
\text { Frequency } \\
\text { (\%) }\end{array}$ & $\begin{array}{l}\text { Non- } \\
\text { adherent } \\
\text { Frequency } \\
(\%)\end{array}$ & $\begin{array}{l}\text { Crude/unadjusted OR } \\
(95 \% \mathrm{Cl})\end{array}$ & p-value & $\begin{array}{l}\text { Adjusted OR } \\
(95 \% \mathrm{Cl})\end{array}$ & p-value \\
\hline \multicolumn{7}{|c|}{ Did the regimen explained to you } \\
\hline Yes & $227(93)$ & $17(7)$ & $7.085(3.57,14.05)$ & $<0.001$ & $7.74(3.14,19.06)$ & $<0.001$ \\
\hline No & $54(72)$ & $21(28)$ & 1 & & 1 & \\
\hline \multicolumn{7}{|c|}{ Adverse effect } \\
\hline Yes & 19(55.9) & $15(44.1)$ & $0.07(0.03,0.16)$ & $<0.001$ & $0.06(0.02,0.18)$ & $<0.001$ \\
\hline No & 262(91.9) & $23(8.1)$ & 1 & & 1 & \\
\hline \multicolumn{7}{|c|}{$\begin{array}{l}\text { Feel comfortable to take drug in front of } \\
\text { others }\end{array}$} \\
\hline Yes & 169(98.8) & $28(1.2)$ & $7.53(3.24,17.52)$ & $<0.001$ & $5.98(2.31,15.50)$ & $<0.001$ \\
\hline No & $112(75.7)$ & $10(24.3)$ & 1 & & 1 & \\
\hline \multicolumn{7}{|c|}{ Attend clinical appointment regularly } \\
\hline Yes & 265(90.1) & 29(9.9) & $4.30(1.76,10.49)$ & $<0.001$ & $4.00(1.06,15.07)$ & 0.04 \\
\hline No & $15(62.5)$ & $9(37.5)$ & 1 & & 1 & \\
\hline
\end{tabular}

continue treatment [29] and their completion rate was worse among those with side effects [30,31]. Patient reports of minor treatment side effects should alert clinicians to reassess and discuss the benefits and the risks of therapy as patient beliefs about the necessity of therapy and concerns about potential adverse effects is a stronger predictor of medication adherence than clinical or socioeconomic factors [32]. Knowledge about the regimen and the disease has significant association with adherence which was inconsistent with the study conducted in Uganda [15]. A cross-sectional study in South Africa also showed no significant association between patients' knowledge about the treatment and the disease with adherence [14]. Knowledge and attitudes towards tuberculosis were not significant predictors in United States [33]. A study conducted to assess factors contributing for poor compliance also showed that knowledge and attitude towards tuberculosis were not significant predictors of adherence [34]. However, other studies reported that beliefs and attitudes may be more important than side effects in predicting adherence and influencing health behavior $[18,35,36]$. Studies reported that patient's compliance with therapy is affected by issues of belief, health motivation, perceived susceptibility to disease and its severity, views in the benefit of professional intervention and knowledge of the condition [37,38]. It has been documented that when patients' know about the importance of complying with drug therapy and their adherence to the prescribed regimen is improved [39]. In similar study in India, it was found that there was an association between the compliance behavior of the patients' and their knowledge of specific aspects of the disease [40]. patients' who perceive their illness to be more serious and who believe that treatment will alleviate the condition are more likely to be compliant [41]. These discrepancies/inconsistencies among different studies may be due to difference on educational status, health service coverage, and access to health related information and level of economic growth across countries. Poor knowledge about treatment regimens and patient perception of benefits obtained from therapy was significantly associated with non adherence $[12,40,42-45]$. This might be due to differences in the study design. Knowledge of factors associated with poor compliance can help to identify groups at risk of defaulting and lead to improved patients' education. Belief in isoniazide (INH) safety was associated with a positive test and patients who believed INH is important for prevention of $\mathrm{TB}$ disease were more likely to be negative urine results [14]. Completers were motivated by understanding the importance of IPT and counseling [28].

This study had some limitations. First, since there is no a "gold standard" for assessment of adherence, we used self-reported adherence which might introduce recall bias. Second, the cross sectional nature of our study may not establish cause effect relationship. Despite the above limitations, the study had several strengths, including using a relatively large sample size, inclusion of several sites, inclusion of several variables and review of available medical charts.

\section{Conclusion}

Adherence rate in Addis Ababa is higher than most studies in Africa. However, stigma, lack of provider-client communication, irregular clinic attendance and fear of side effects of the medication were the best predictor's of non-adherence. Health workers and the ministry of 
health should design and deliver tailored health education messages on the aforementioned risk factors for clients to promote better adherence.

\section{Acknowledgements}

This study was funded by Jimma University. We thank all participants for devoting their time to take part in this study.

\section{Author details}

'Department of General Public Health, College of Public Health and Medical Science, Jimma University, Jimma, Ethiopia. ${ }^{2}$ Department of Epidemiology, College of Public Health and Medical Science, Jimma University, Jimma, Ethiopia.

\section{Authors' contributions}

MM conceived and designed the study and collected data in the field, performed analysis, interpretation of data, and draft the manuscript. AD assisted with the design, interpretation of data and the critical review of the manuscript. FT participated in design and helped to draft the manuscript and critically reviewed the manuscript. SB assisted with the design, interpretation of data, draft and critical review of the manuscript. All authors approved and read the final manuscript. All authors participated in critical appraisal and revision of the manuscript.

\section{Competing interests}

The authors declare that they have no competing interests.

Received: 12 April 2011 Accepted: 12 December 2011

Published: 12 December 2011

\section{References}

1. Smoll M, Shafer F: An out breaks of tuberculosis with accelerated progression among person infected with HIV. New Engl J Med 2006, 326:213-35.

2. World Health Organization (WHO): Global Tuberculosis Control-surveillance, Planning, Financing WHO/HTM/TB/2006.362. Geneva: WHO; 2006.

3. Dye C, Watt CJ, Bleed DM, Hosseini SM, Raviglione MC: Evolution of tuberculosis control and prospects for reducing tuberculosis incidence, prevalence, and deaths globally. JAMA 2005, 293:2767-75.

4. MOH: AIDS in Ethiopia, disease prevention and control department of ministry of health., 42008

5. Moulding T, Dutt A, Reichman L: Fixed-dose combinations of anti tuberculosis medications to prevent drug resistance. Ann Intern Med 2006, 122:951-54.

6. WHO/UNAIDS: Policy Statement on Preventive Therapy Against Tuberculosis in People Living with HIV.WHO/TB/98.255 Geneva: WHO; 2005.

7. MOH: Implementation Guidelines for TB/HIV Collaborative Activities in Ethiopia Addis Ababa: Federal Ministry of Health; 2008.

8. International Union against Tuberculosis and Lung Disease, Global Program on AIDS, World Health Organization: Tuberculosis preventive therapy in HIV-infected individuals. A joint statement of the International Union Against Tuberculosis and Lung Disease (IUATLD) and the Global Program on AIDS and the Tuberculosis Program of the World Health Organization (WHO). Tubercle Lung Dis 1994, 75:96-98.

9. Besch CL: Compliance in clinical trials. AIDS 2004, 9(1):1-10.

10. Winkvist A, Diwan V: Adherence to IPT among HIV infected person in Chaiang Rai Thailand. AIDS 2007, 11:107-112.

11. Foster S, Godfry-Faussett P, Porter, Modeiling J: Adherence to tuberculosis preventive therapy for people live with HIV; the example of Uganda. AIDS 2002, 11(3):919-925.

12. Rowe K, Makhubele J, Hargreaves R: Adherence to TB preventive therapy for HIV-positive patients in rural South Africa: implications for antiretroviral delivery in resource-poor settings? Int I Tuberc Lung Dis 2005, 9(3):263-269.

13. Hiransuthikul N, Nelson KE, Hiransuthikul P, Vorayingyong A, Paewplot R: INH preventive therapy among adult HIV-infected patients in Thailand. Int J Tuberc Lung Dis 2005, 9(3):270-5.
14. Szakacs TA, Wilson D, Cameron DW, Clark M, Kocheleff P, Muller FJ, McCarthy AE: Adherence with isoniazid for prevention of tuberculosis among HIV-infected adults in South Africa. BMC Infect Dis 2006, 13:6:97.

15. Wilkinson D: Effect of preventive treatment for tuberculosis in adults infected with HIV: systematic review of randomized placebo controlled trials. BMJ 2005, 317:625-629.

16. McCallum R: Effects of previous medication experience and health beliefs on intended compliance to an imagined regimen. $J$ Compliance in Health Care 2007, 3:125-134.

17. Meichenbaum D, Turk D: Facilitating Treatment Adherence: A Practioner's Guidebook New York: Plenum Press; 2006.

18. Rennie TW, Bothamley GH, Engova D, Bates IP: Patient choice promotes adherence in preventive treatment for latent tuberculosis. Eur Respir $J$ 2007, 30:728-735.

19. Dunbar J: Predictors of patient adherence: patient characteristics. In The Handbook of Health Behavior Change. Edited by: Shumaker S, Schroon E, Ockene J. New York: Springer; 2004:348-360.

20. Bartlett EE: The effects of physician communications skills on patient satisfaction; recall, and adherence. J Chronic Dis 2001, 37(9-10):755-64.

21. Sbarbaro JA: The patient-physician relationship: compliance revisited. Ann Allergy 2006, 64(4):325-31.

22. Clark NM: Impact of education for physicians on patient outcomes. Pediatrics 2004, 101(5):831-6.

23. Clark NM: Long-term effects of asthma education for physicians on patient satisfaction and use of health services. Eur Respir J 2000, 16(1):15-21.

24. Stewart MA: Effective physician-patient communication and health outcomes: a review. Can Med Assoc J 2006, 152(9):1423-33.

25. Mead N, Bower P: Patient-centered consultations and outcomes in primary care: a review of the literature. Patient Educ Couns 2002 48(1):51-61.

26. Korsch BM, Negrete VF: Doctor-patient communication. Sci Am 2003, 227(2):66-74.

27. Xu W, Lu W, Zhou Y, Zhu L, Shen H, Wang J: Adherence to antituberculosis treatment among pulmonary tuberculosis patients: a qualitative and quantitative study. BMC Health Serv Res 2009, 9:169.

28. Munseri PJ, Talbot EA, Mtei L, Fordham von Reyn C: Completion of isoniazid preventive therapy among HIV-infected patients in Tanzania. Int J Tuberc Lung Dis 2008, 12:1037-1041.

29. Philip A, LoBue, Kathleen S, Moser : Use of isoniazid for latent tuberculosis infection in a public health clinic. Am J Respir Crit Care Med 2003, 168:443-447.

30. Page KR, Sifakis F, Montes de Oca R, et al: Improved adherence and less toxicity with rifampin vs isoniazid for treatment of latent tuberculosis. Arch Intern Med 2006, 166:1863-1870.

31. Kwara A, Herold JS, Machan JT, Carter EJ: Factors associated with failure to complete isoniazid treatment for latent tuberculosis infection in Rhode Island. Chest 2008, 133(4):862-8.

32. Horne $R$, Weinman J: Patients' beliefs about prescribed medicines and their role in adherence to treatment in chronic physical illness. J Psychoomat Res 1999, 47:555-567.

33. Hirsch-Moverman Y, Bethel J, Colson PW, Franks J, El-Sadr W: Predictors of latent tuberculosis infection treatment completion in the United States: an inner city experience. Int J Tuberc Lung Dis 2010, 14:1104-11.

34. Naing NN, D'Este C, Isa AR, Salleh R, Bakar N, Mahmod MR: Factors contributing to poor compliance with anti-TB treatment among tuberculosis patients. Southeast Asian J Trop Med Public Health 2001, 32(2):369-82.

35. Parsyan AE, Saukkonen J, Barry MA, Sharnprapai S, Horsburgh CR Jr: Predictors of failure to complete treatment for latent tuberculosis infection. J Infect 2007, 54:262-266.

36. Shieh FK, Snyder G, Horsburgh CR, Bernardo J, Murphy C, Saukkonen JJ: Predicting non- completion of treatment for latent tuberculosis infection: a prospective survey. Am J Respir Crit Care Med 2006, 174:717-721.

37. Rosenstock IM: Patient compliance with health regimens. JAMA 1975, 234:402-3.

38. Sloan JP, Sloan MC: An assessment of default and non - compliance in tuberculosis control in Pakistan. Trans R Soc Trop Med Hyg 1981, 75:717-8. 
39. Stewart MA: What is the successful doctor-patient interview? A study of interactions and outcomes. Soc Sci Med 1984, 19:167-75.

40. Barnhoorn $\mathrm{F}$, Adriaanse $\mathrm{H}$ : In search of factors responsible for noncompliance among tuberculosis patients in Wardha District, India. Soc Sci Med 1992, 34(3):291-306.

41. O'Hanrahan M, O'Malley K: Compliance with drug treatment. Br Med J 283:298-300

42. Alcabes P: Compliance with isoniazid prophylaxis in jail. Am Rev Respir Dis 2006, 140(5):1194-7.

43. Menzies R, Rocher I, Vissandjee B: Factors associated with compliance in treatment of tuberculosis. Tuber Lung Dis 2002, 74(1):32-7.

44. Janz NK, Becker MH: The Health Belief Model: a decade later. Health Educ Q 2004, 11(1):1-47.

45. Becker M: The health belief model and personal behavior. Health Educ Monogr 2000, 1:324-508.

\section{Pre-publication history}

The pre-publication history for this paper can be accessed here: http://www.biomedcentral.com/1471-2458/11/916/prepub

doi:10.1186/1471-2458-11-916

Cite this article as: Mindachew et al:: Predictors of adherence to

isoniazid preventive therapy among HIV positive adults in Addis Ababa,

Ethiopia. BMC Public Health 2011 11:916.

\section{Submit your next manuscript to BioMed Central} and take full advantage of:

- Convenient online submission

- Thorough peer review

- No space constraints or color figure charges

- Immediate publication on acceptance

- Inclusion in PubMed, CAS, Scopus and Google Scholar

- Research which is freely available for redistribution

Submit your manuscript at www.biomedcentral.com/submit 